\title{
Imaging patients with suspected brain tumour: guidance for primary care
}

David P Kernick, Fayyaz Ahmed, Anish Bahra, Andrew Dowson, Giles Elrington, Manuela Fontebasso, Nicola J Giffin, Sue Lipscombe, Anne MacGregor, Richard Peatfield, Stuart Weatherby, Tom Whitmarsh and Peter J Goadsby

\begin{abstract}
The number of referrals by primary care practitioners to secondary care neurology services, particularly for headache, may be difficult to justify. Access to imaging by primary care practitioners could avoid referral without compromising patient outcomes, but the decision to refer is based on a number of complex factors. Due to the paucity of rigorous evidence in this area, available data are combined with expert opinion to offer support for GPs. The study suggests management for three levels of risk of tumour: red flags $>1 \%$; orange flags $0.1-1 \%$; and yellow flags $<0.1 \%$ but above the background population rate of $0.01 \%$. Clinical presentations are stratified into these three groups. Important secondary causes of headache where imaging is normal should not be overlooked, and normal investigation does not eliminate the need for follow-up or appropriate management of headache. Keywords

brain tumour; diagnosis; imaging; primary care.
\end{abstract}

DP Kernick, St Thomas Health Centre, Exeter. F Ahmed, Hull Royal Infirmary, Hull. A Bahra, Institute of Neurology, University College London, National Hospital for Neurology and Neurosurgery. A Dowson, King's College Hospital; G Elrington, Centre for Neurosciences, Bart's and the London NHS Trust; A MacGregor, The City of London Migraine Clinic; $R$ Peatfield, Princess Margaret Migraine Clinic, Charing Cross Hospital; PJ Goadsby, Institute of Neurology, University College London, National Hospital for Neurology and Neurosurgery, London. M Fontebasso, Headache Clinic, Department of Neurosciences, York Hospital, York. NJ Giffin, Department of Neurology, Royal United Hospital, Bath. S Lipscombe, Park Crescent Surgery, Brighton. S Weatherby, Department of Neurology, Derriford Hospital, Plymouth. T Whitmarsh, Glasgow Homeopathic Hospital, Glasgow. On behalf of The British Association for the Study of Headache, Department of Neurology, Hull Royal Infirmary, Hull.

Address for correspondence Dr David Kernick, St Thomas Health Centre, Cowick Street, Exeter EX4 1HJ. E-mail: su1838@eclipse.co.uk

Submitted: 13 May 2008; Editor's response: 2 July 2008; final acceptance: 1 September 2008.

(c)British Journal of General Practice 2008; 58: 880-885.

DOI: 10.3399/bjgp08X376203

\section{INTRODUCTION}

The annual incidence of brain tumour in the UK is approximately $0.06-0.01 \%$, of which $72 \%$ of people with brain tumour will present above the age of 50 years. ${ }^{1,2}$ Although a brain tumour can present with a number of signs or symptoms, a headache presentation is invariably a cause for concern for both patient and doctor.

In primary care in the UK, the annual consultation rate for headache is 4.4 per 100 patients, of whom $3 \%$ are referred to secondary care for further assessment. $^{3}$ Direct referral by the GP to brain imaging is also becoming increasingly available.

The decision to investigate headache is based on a number of complex factors that include therapeutic value, clinical confidence, time constraints within the consultation, availability of imaging, the GP's approach to risk and uncertainty, reassurance of an anxious patient, and medicolegal concerns. ${ }^{4,5}$ The context in which the decision is made also plays an important part. In primary care, GPs experience difficulty in diagnosing headaches, ${ }^{6}$ while in secondary care, patients will often anticipate the exclusion of secondary pathology and consultants will be under pressure to make a diagnosis at the first appointment.

These factors result in wide variations in GP referral rates for headache. ${ }^{7}$ A $B M J$ editorial suggested that for headache presentations, the lowest common denominator that directs behaviour is what a convincing expert might tell a court. ${ }^{8}$

In view of the complexity of the area and the fact that effective communication improves patient health outcomes, ${ }^{9}$ there is a need for pragmatic guidance to support the practitioner. Although a number of guidelines have been developed, ${ }^{10,11}$ the focus has been on secondary care, and guidance is hedged with uncertainties. Recent guidelines for primary care have been developed by the National Institute for Health and Clinical Excellence, ${ }^{12}$ but their review of the existing evidence base and guidance is limited. 
As population screening for brain tumour is not appropriate, ${ }^{13}$ a guideline needs to address two questions:

- against a background annual population risk of a tumour presentation of $0.01 \%$, at what level of risk should imaging be undertaken?

- are there clinical symptoms or signs that indicate a particular level of risk?

Ideally, guidelines should be developed from rigorous studies that are integrated into decision pathways. This approach would require a large number of consecutive patients in relevant settings, prospective randomised studies, and blind interpretation of data: a standard that is unlikely to be achieved for such a rare condition. Current studies are limited by small sample sizes, a wide range of estimates, retrospective recall bias, specialist centre focus across and conflation of acute and chronic presentations. Many studies report computed tomography (CT) investigation that is less sensitive than magnetic resonance imaging (MRI), while sensitivity in both modalities has improved with time, making comparison of studies difficult. There is also uncertainty over what constitutes 'significant pathology' and the relevance of abnormal findings to clinical presentations. Inevitably, professional consensus is required that combines evidence with clinical experience.

The objective of this paper is to provide pragmatic support to practitioners for investigation of suspected brain tumour. The Science Citation Index and Social Sciences Citation of the Web of Science were searched for relevant entries to December 2007. An expert panel comprising primary and secondary care members of the British Association for the Study of Headache identified any gaps in the literature base and provided specialist input.

This paper is constructed in three parts. First, it suggests levels of risk of brain tumour at which investigation should be undertaken. Secondly, it ascribes clinical signs and symptoms to the risk of brain tumour. Finally, it combines this evidence with clinical experience to offer clinical guidance for GPs.

\section{AT WHAT LEVEL OF RISK OF BRAIN TUMOUR SHOULD IMAGING BE UNDERTAKEN?}

From a rational perspective, against a background of limited healthcare resources, the level of risk at which imaging takes place is directed by costutility analysis; that is, the cost of each incremental quality-adjusted life year (QALY) gained compared

\section{How this fits in}

Although brain tumour can present with a number of signs or symptoms, a presentation of headache is invariably a cause for concern for both patient and doctor. The decision to investigate for tumour is based on a number of complex factors. Although guidelines for investigation have been developed, the focus is on secondary care, and support for GPs is limited. In this paper, expert opinion is combined with available evidence to offer pragmatic support for GPs when brain tumour is suspected. Three levels of risk and corresponding appropriate management are suggested: red flags, orange flags, and yellow flags. Clinical presentations are stratified into these three groups.

with alternative investments. ${ }^{14}$ There is a paucity of research on decision and economic analysis of imaging strategies for brain tumour. ${ }^{15}$ Only one economic model has been published in an investigation of tumour in children with headache. ${ }^{16}$ For high-risk groups, defined as a $4 \%$ level of risk, MRI yielded a cost per QALY that was over twice the currently accepted guidelines.

However, due to the methodological difficulties involved in deriving meaningful economic evidence in this area, determining the level of risk at which imaging is indicated will involve a subjective value judgement that integrates the benefits and disadvantages of imaging, and a comparison with risks where investigations are undertaken in other clinical areas.

\section{Benefits of imaging}

Potential for improvement in quality and quantity of life will vary widely between types of lesion, and in many cases may be marginal. Many patients and doctors will obtain reassurance from the exclusion of serious pathology. However, studies examining the effects of referral for headache on clinical outcomes in terms of symptoms and patient anxiety produce conflicting findings. ${ }^{17-19}$ Merely asserting that nothing is wrong may deny the reality of patient concerns,,$^{20}$ and spending more time during a consultation directly discussing a patient's concerns may reduce the need for unnecessary tests. ${ }^{21}$

\section{Disadvantages of imaging}

The identification of incidental pathology, its clinical relevance, and the unnecessary anxiety it incurs is well recognised and can be significant. Imaging studies in asymptomatic populations yield abnormalities ranging from $0.6 \%$ to $2.8 \% .^{22-24}$ These findings may also have implications for future life insurance applications. MRI is distressing to a number of patients, while the radiation exposure from CT should not be overlooked. 
Box 1. Three levels of risk of brain tumour and suggested management.

- Red flags - presentations where the probability of an underlying tumour is likely to be greater than $1 \%$. These warrant urgent investigation.

- Orange flags - presentations where the probability of an underlying tumour is likely to be between 0.1 and $1 \%$. These need careful monitoring and a low threshold for investigation.

Yellow flags - presentations where the probability of an underlying tumour is likely to be less than $0.1 \%$ but above the population rate of $0.01 \%$. These require appropriate management but the need for follow-up is not excluded.

\section{Comparison with other clinical areas}

Comparative risk rates of presentations in other clinical areas may help to establish a level of risk where further investigation is deemed appropriate. For example, 1-year positive predictive values for carcinoma of the colon are: weight loss $1.2 \%$, rectal bleeding 2.4-3.4\%, faecal occult blood $7 \% .{ }^{25,26}$ The predictive value for haemoptysis in carcinoma of the lung is $2.4 \% .^{27}$

On the basis of the above inputs, the suggestion is to define three levels of risk as shown in Box 1.

\section{WHAT CLINICAL SYMPTOMS OR SIGNS INDICATE A PARTICULAR LEVEL OF RISK? \\ Headache}

Seventy per cent of patients with brain tumour will have headache at some time in their illness. The frequency at the time of diagnosis is confounded by recollection bias, and varies with clinical setting between $23 \%$ and $56 \%{ }^{28-30}$ In primary care, the risk of brain tumour with a headache presentation is $0.09 \% .^{31}$ There is no consistent clinical pattern to the features of headache associated with tumour, and the location of the pain is not usually related to the position of the lesion. One study found headaches similar to tension-type in $77 \%$ and to migraine in $9 \%$ of patients. ${ }^{32}$

Headache with associated features. A recent review of the literature of headache with associated features $^{33}$ found the following relevant positive likelihood ratios (likelihood ratio $=$ post probability/prior probability) with $95 \%$ confidence intervals $(95 \% \mathrm{Cls})$ : headache with abnormal findings on clinical neurological examination 5.3 $(95 \% \mathrm{Cl}=2.4$ to 12$)$; headache aggravated by exertion or Valsalva-like manoeuvre $2.3(95 \% \mathrm{Cl}=$ 1.4 to 3.8$)$; headache with vomiting $1.8(95 \% \mathrm{Cl}=$ 1.2 to 2.6); headache with focal symptoms 3.1 $(95 \% \mathrm{Cl}=0.37$ to 25$)$; worsening headache 1.6 $(95 \% \mathrm{Cl}=0.23$ to 10$)$; and cluster headache 10.7 $(95 \% \mathrm{Cl}=2.2$ to 52$)$. Another review has given rapidly increasing headache frequency $12(95 \% \mathrm{Cl}$ = 3 to 48); headache causing awakening from sleep $98(95 \% \mathrm{Cl}=10$ to 960$)$; and dizziness or lack of coordination $49(95 \% \mathrm{Cl}=3$ to 710$) .{ }^{11}$ The majority of studies reviewed were from secondary care. Table 1 shows the above data applied to the pretest probability of $0.09 \%$ for tumour with headache in primary care.

Isolated headache. Isolated headache where there are no accompanying signs or clear diagnostic pattern is a difficult presentation for the GP. Estimates of the proportion of patients with tumour who present with isolated headache range between $2 \%$ and $16 \%{ }^{28,34,35}$

If the GP can make a diagnosis of a primary headache at presentation (migraine, tension-type, or cluster), the risk of tumour is $0.045 \%$. If a diagnosis cannot be made, the risk is $0.15 \%{ }^{36} \mathrm{~A}$ recent secondary care study found that in the $10 \%$ of headaches where no diagnosis could be made,

Table 1. Best estimates of risk of tumour with headache presentations in primary care and associated features. Derived from primary care pretest probability $(0.09 \%)$ and likelihood ratios derived mainly from secondary care.

\begin{tabular}{lcc} 
Clinical feature & $\begin{array}{c}\text { Likelihood ratio } \\
(95 \% \text { Cls })\end{array}$ & $\begin{array}{c}\text { Risk of tumour in headache } \\
\text { presentations in primary care, \% }\end{array}$ \\
\hline Headache causing waking from sleep & $98(10$ to 960$)$ & 9 \\
\hline Dizziness or lack of coordination & $49(3$ to 710$)$ & 4 \\
\hline Rapidly increasing headache frequency & $12(3$ to 48$)$ & 1 \\
\hline Abnormal neurological examination & $5.3(2.4$ to 12$)$ & 0.5 \\
\hline Headache with focal neurological symptoms & $3.1(0.37$ to 25$)$ & 0.3 \\
\hline Aggravated by exertion or Valsalva-like manoeuvre & $2.3(1.4$ to 3.8$)$ & 0.2 \\
\hline Associated vomiting & $1.8(1.2$ to 2.6$)$ & 0.2 \\
\hline Worsening headache & $1.6(0.23$ to 10$)$ & 0.1 \\
\hline
\end{tabular}


the risk of abnormality was $3.7 \% \cdot{ }^{37}$ The risk in migraine was $0.4 \%$ and in tension-type headache $0.8 \%$. Previous secondary care studies of consecutive non-acute isolated headache quoted abnormalities for migraine as $0-3.1 \%$ and unspecified headache $0-6.7 \% .^{10}$

A secondary care prospective study suggested that headache without the development of additional signs or symptoms for longer than 11 weeks after initial presentation will only be due to a tumour in exceptional cases. ${ }^{38}$ In primary care, if a tumour is present and a headache diagnosis cannot be made at presentation, $74 \%$ of tumours will have presented by 3 months, and $90 \%$ by 6 months. ${ }^{36}$

With isolated headache, the emphasis is on monitoring and allowing a diagnostic pattern to emerge. Extra vigilance is advisable in patients over 50 years, where the incidence of underlying pathology is higher. The suggestion is that if a diagnostic pattern has not emerged at 8 weeks after an isolated headache presentation to primary care, then investigation should be considered following discussion with the patient.

Practical clinical guidance for new isolated headache presentations that need a diagnostic pattern to emerge can be found on the British Association for the Study of Headache website (http://www.bash.org.uk).

Headache with a history of cancer elsewhere. Brain metastases occur in $20-40 \%$ of patients with cancer. ${ }^{39}$ Lung ( $43 \%$ of secondary tumours) and breast ( $8 \%$ of secondary tumours) are the predominant primary locations. Thirty-two per cent of cancer patients presenting with new or changed headache will have intracranial metastases, and in most cases the primary tumour will have been identified. ${ }^{40}$ New headache in patients with a history of cancer should always be treated with suspicion.

\section{Non-headache presentations}

Other symptoms of tumour that have been quantified in primary care are new-onset seizure $1.2 \%(95 \% \mathrm{Cl}=1.0$ to 1.4$)$, confusion $0.20 \%(95 \%$ $\mathrm{Cl}=0.16$ to 0.24$)$, weakness $0.14 \%(95 \% \mathrm{Cl}=0.11$ to 0.18$)$, motor loss $0.026 \%(95 \% \mathrm{Cl}=0.024$ to $0.030)$, and memory loss $0.036 \%(95 \% \mathrm{Cl}=0.026$ to 0.052$).{ }^{31}$ Personality change has also been reported but not quantified.

\section{The importance of age}

The risks given above are across all age groups. Higher levels of suspicion are required with increasing age. Table 2 is taken from primary care
Table 2. Relative risk of tumour (age 18-29 years as base rate).

Relative risk of tumour against base rate at 18-29 years

\begin{tabular}{ll} 
Age band, years & (2.6 tumours/year/100 000 population) \\
\hline $18-29$ & 1.0 \\
\hline $30-39$ & 1.5 \\
\hline $40-49$ & 2.2 \\
\hline $50-59$ & 4.3 \\
\hline $60-69$ & 6.9 \\
\hline $70-79$ & 7.9 \\
\hline 80 & 5.9 \\
\hline
\end{tabular}

data, ${ }^{31}$ and shows increased risk of tumour with age against a baseline risk at age range 18-29 years.

\section{GUIDANCE FOR PRIMARY CARE PRACTITIONERS ON IMAGING PATIENTS WITH SUSPECTED BRAIN TUMOUR}

Based on the above evidence and confidence intervals, and combined with the authors' clinical experience, guidance for investigating for brain tumour in primary care is set out in Box 2. This suggests appropriate management for different

\section{Box 2. Recommended guidance for investigating for tumour} in primary care.

Red flags - presentations where the probability of an underlying tumour is likely to be greater than $1 \%$. These warrant urgent investigation.

- Papilloedema

- Significant alterations in consciousness, memory, confusion, or coordination

- New epileptic seizure

- New-onset cluster headache (imaging, particularly of the region of the pituitary fossa, required but non-urgent)

- Headache with a history of cancer elsewhere particularly breast and lung

- Headache with abnormal findings on neurological examination or other neurological symptoms (although evidence base suggests orange flag)

- Orange flags - presentations where the probability of an underlying tumour is likely to be between 0.1 and $1 \%$. These need careful monitoring and a low threshold for investigation.

- New headache where a diagnostic pattern has not emerged after 8 weeks from presentation

- Headache aggravated by exertion or Valsalva-like manoeuvre

- Headaches associated with vomiting

- Headaches that have been present for some time but have changed significantly, particularly a rapid increase in frequency

- New headache in a patient over 50 years

- Headaches that wake the patient from sleep

- Confusion

Yellow flags - presentations where the probability of an underlying tumour is likely to be less than $0.1 \%$ but above the population rate of $0.01 \%$. These require appropriate management, and the need for follow-up is not excluded.

- Diagnosis of migraine or tension-type headache

- Weakness or motor loss

- Memory loss

- Personality change 
levels of risk and the features that define that risk.

\section{CONCLUSION}

This paper has described guidance for primary care practitioners when brain tumour is suspected. The guidance is based on expert opinion combined with the limited studies that are available. The majority of these have been undertaken in secondary care, based on poor methodology, and often report wide confidence intervals.

In view of the significant level of incidental findings and lesions of uncertain clinical significance, the decision to image a patient should not be taken lightly. In many cases, the current developments allowing for increasing sensitivity and reducing cost of investigation are divorced from current understanding of the natural history of lesions that are identified.

Ultimately, the decision to investigate should be taken jointly with the patient. Direct discussion of patient concerns and the implications of imaging may be more likely to reassure patients than unnecessary tests or consultant referral, although there is evidence that imaging may be a costeffective way to reassure a proportion of patients with high anxiety levels.

In the absence of a rigorous evidence base, medicolegal case law can be an important precedent. A review of published primary care case studies suggests that problems arise not when subtle signs or symptoms are missed, but from failure to identify and adequately record gross neurological findings (http://www.medicalprotection.org and http://www. the-mdu.com). A successful defence depends on whether the practitioner has investigated the presenting symptom to an appropriate degree, and whether any delay incurred in order to establish a diagnosis that would significantly affect the prognosis.

The authors make no recommendations for the type of investigation. Although $\mathrm{MRI}$ is a more accurate modality, cost and availability will dictate the use of CT in many areas. It is important to emphasise that a normal investigation of any type does not exclude the need for further follow-up. There are some important secondary causes of headache where imaging can be normal, and a normal investigation does not eliminate the need for appropriate management of primary headache.

Access to imaging by primary care practitioners supported by the framework proposed in this article could avoid referral and inappropriate investigation without compromising patient outcomes. Studies comparing GPs with and without access to imaging are needed to support policy development in this important area.

\section{Competing interests}

The authors have stated that there are none.

\section{Discuss this article}

Contribute and read comments about this article on the

Discussion Forum: http://www.rcgp.org.uk/bjgp-discuss

\section{REFERENCES}

1. Office for National Statistics. Series MBI No 25. London: Office for National Statistics, 1998

2. Counsell C, Grant R. Incidence studies of primary and secondary intracranial tumours: a systematic review of their methodology and results. J Neuro-Oncol 1998; 37(3): 241-250.

3. Latinovic R, Gulliford M, Ridsdale L. Headache and migraine in primary care: consultation, prescription and referral rates in a large population.

I Neurol Neurosurg Psychiatry 2006; 77(3): 385-387.

4. Couchman G, Forjuoh S, Rajab M, Phillips C, Yu J. Non-clinical factors associated with primary care physicians ordering patterns of magnetic resonance imaging/computer tomography for headache. Acad Radiol 2004; 11(7): 735-740.

5. Morgan M, Jenkins L, Ridsdale L. Patient pressure for referral for headache: a qualitative study of GPs' referral behaviour. $\mathrm{Br} \mathrm{J} \mathrm{Gen}$ Pract 2007; 57(534): 29-35.

6. Kernick D, Stapley S, Hamilton W. GPs' classification of headache: is primary headache underdiagnosed? Br J Gen Pract 2008; 58(547): 102-104.

7. Ridsdale L, Clarke L, Dowson, et al. How do patients referred to neurologists with headache differ to those managed in primary care?

Br J Gen Pract 2007; 57(538): 388-395.

8. Goadsby P. To scan or not to scan in headache. BMJ 2004; 329(7464): 469-470.

9. Stewart M. Effective physician patient communication and health outcomes: a review. Can Med Assoc J 1995; 152(9): 1423-1433.

10. Sandrini G, Friberg L, Janig W, et al. Neurophysiological tests and neuroimaging procedures in non-acute headache: guidelines and recommendations. Eur J Neurol 2004; 11(4): 217-224.

11. American Academy of Neurology. Report of the Quality Standards Sub-Committee of the American Academy of Neurology. The utility of neuro imaging in the evaluation of headache in patients with normal neurological examinations.

www.aan.com/professionals/practice/pdfs/gl0088.pdf (accessed 20 Oct 2008).

12. National Institute for Health and Clinical Excellence. Referral guidelines for suspected cancer. NICE, 2005. http://www.nice.org.uk/nicemedia/ pdf/cg027niceguideline.pdf (accessed 22 Oct 2008)

13. Steiger H. Preventive neurosurgery: population-wide check-up examinations and correction of asymptomatic pathologies of the nervous system. Acta Neurochirurgica 2006; 148(10): 1075-1083.

14. Robinson R. Cost utility analysis. BMJ 1993; 307(6908): 859-862.

15. Hutter A, Schwetye KE, Bierhals AJ, McKinstry RC. Brain neoplasms: epidemiology, diagnosis, and prospects for costeffective imaging. Neuroimaging Clin North Am 2003; 13(2): 237.

16. Medina LS, Kuntz K, Pomeroy S. Children with headache suspected of having a brain tumor: a cost-effectiveness analysis of diagnostic strategies. Pediatrics 2001; 108(2): 255-263.

17. Fitzpatrick R, Hopkins A, Harvard-Watts O. Social dimensions of healing: a longitudinal study of outcomes of medical management of headaches. Soc Sci Med 1983; 17(8): 501-510.

18. Howard L, Wessely S, Leese M, et al. Are investigations anxiolitic or anxiogenic? A randomised controlled trial of neuroimaging to provide reassurance in chronic daily headache. J Neurol Neurosurg Psychiatry 2005; 76(11): 1558-1564.

19. Fitzpatrick R, Hopkins A. Referrals to neurologists for headaches not due to structural disease. J Neurol Neurosurg Psychiatry 1981; 44(12): 1061-1067.

20. Kessel N. Reassurance. Lancet 1979; 1(8126): 1128-1133.

21. Fitzpatrick R. Telling patients there is nothing wrong. BMJ 1996; 313(7053): 311-312.

22. Katzman G, Dagher A, Patronas N. Incidental findings on brain magnetic resonance imaging from 1000 asymptomatic volunteers. JAMA 1999; 282(1): 36-39.

23. Yue N, Longstreth W Jr, Elster A, et al. Clinically serious 
abnormalities found incidentally at MRI imaging of the brain: data from the Cardiovascular Health Study. Radiology 1997; 202(1): $41-46$.

24. Weber F, Knopf $\mathrm{H}$. Incidental findings in magnetic resonance imaging of the brains of healthy young men. J Neurol Sci 2005; 240(1-2): 81-84.

25. Hamilton W, Round A, Sharp D, Peters T. Clinical features of colorectal cancer before diagnosis: a population-based case-contro study. Br J Cancer 2005; 93(4): 399-405.

26. Ellis B, Thompson M. Factors identifying higher risk recta bleeding in general practice. Br J Gen Pract 2005; 55(521): 949-955.

27. Hamilton W, Peters T, Round A, Sharp D. What are the clinical features of lung cancer before the diagnosis is made? A population based case-control study. Thorax 2005; 60(12): 1059-1065.

28. Suwanwela N, Phanthumchinda K, Kaoropthum S. Headache in brain tumour: a cross-sectional study. Headache 1994; 34(7): 435-438.

29. Jaeckle K. Causes and management of headaches in cancer patients. Oncology 1993; 7(4): 27-31

30. Snyder H, Robinson K, Shah D, et al. Signs and symptoms of patients with brain tumors presenting to the emergency department. J Emerg Med 1993; 11(3): 253-258.

31. Hamilton W, Kernick D. Clinical features of primary brain tumours: a case controlled study using primary care records. $\mathrm{Br} J$ Gen Pract 2007; 57(542): 695-699.
32. Forsyth P, Posner J. Headaches in patients with brain tumours: a study of 111 patients. Neurology 1993; 43(9): 1678-1683.

33. Detsky M, McDonald D, Baerlocher M, et al. Does this patient with headache have a migraine or need neuro imaging? JAMA 2006; 296(10): 1274-1283.

34. Grant R. Overview: brain tumour diagnosis and management. Royal College of Physicians Guidelines. J Neurol Neurosurg Psychiatry 2004; 75(Suppl 2): 18-23.

35. Iversen H. Strange P, Sommer W, Tjalve E. Brain tumour headache related to tumour size, and location. Cephalalgia 1987; Suppl 6: 394-395.

36. Kernick D, Stapley S, Goadsby PJ, Hamilton W. What happens to new-onset headache presented to primary care? A case-cohort study using electronic primary care records. Cephalalgia 2008; 28(11): 1188-1195.

37. Sempere A, Porta-Etessam J, Medrano V, et al. Neuroimaging in the evaluation of patients with non-acute headache. Cephalalgia 2005; 25(1): 30-35.

38. Vazquez-Barquero A, Ibanez F, Herrera S, et al. Isolated headache as the presenting clinical manifestation of intracranial tumors: a prospective study. Cephalalgia 1994; 14(4): 270-272.

39. Soffietti R, Ruda R, Mutani R. Management of brain metastases. J Neurol 2002; 249(10): 1357-1369.

40. Christiaans MH, Kelder JC, Arnoldus EP, Tijssen CC. Prediction of intracranial metastases in cancer patients with headache. Cancer 2002; 94(7): 2063-2068. 